\title{
A COMPARATIVE STUDY OF LAPAROTOMY WOUND CLOSED WITH PROFESSOR HUGHES FAR NEAR TECHNIQUE WITH NYLON AND INTERRUPTED-X TECHNIQUE WITH VICRYL
}

\author{
Sanjeev Sharma ${ }^{1}$, Sukkha Singh ${ }^{2}$, Chithra Thomas ${ }^{3}$ \\ 1 Professor and HOD, Department of Surgery, GMC, Amritsar, Punjab, India. \\ ${ }^{2}$ Assitant Professor, Department of Surgery, GMC, Amritsar, Punjab, India. \\ 3Junior Resident, Department of Surgery, GMC, Amritsar, Punjab, India.
}

\section{BACKGROUND}

ABSTRACT

There is a debate about the best method of closure of midline vertical laparotomy wound following exploratory laparotomy. This debate has gained importance because one common complication of exploratory laparotomy is burst abdomen or abdominal wound dehiscence, which is associated with high morbidity, mortality and cost of care. There are a number of studies evaluating various closure techniques and suture materials. Studies carried out in the west have found no significant difference in the risk of burst between continuous and interrupted methods. The choice of closure methods may not be very crucial in patients undergoing elective laparotomy with adequate nutritional status and no other risk factors for bursts, unlike developing countries like ours where most patients present with one or more of risk factors such as malnutrition prolonged intra peritoneal sepsis. Hence it is imperative to ascertain the safest method of closing the laparotomy wound. We wanted to compare interrupted X method and professor Hughes far near technique, to identify the better method of closing midline laparotomy wound.

\section{METHODS}

This non-randomized controlled trial was done on patients admitted in the department of surgery, Government Medical College, Amritsar, from July 2016 to August 2018. 40 Patients taken up for midline laparotomy were divided into two groups with 20 in each group. Sample size was taken for convenience. In group-1 patients, interrupted-X technique with Vicryl was used for closing the sheath and in group-2 professor Hughes' far near technique with nylon was used. Intraoperative time taken, suture length, wound length, post-operative wound infection, wound dehiscence \& burst abdomen ang suture sinus rates were assessed.

\section{RESULTS}

The operative time taken was lesser in group-2 patients in whom, Professor Hughes' far near technique was used. The suture to wound length ratio was more than 4:1 proven by Jenkins rule and the results were statistically significant. Wound infection, wound dehiscence and burst abdomen rates were less in group-2 patients than in group 1 patients but suture sinus rates were increased in group- 2 .

\section{CONCLUSIONS}

Professor Hughes technique with nylon is less time consuming with lesser wound infection, wound dehiscence and burst abdomen rates than interrupted-X method with Vicryl.

HOW TO CITE THIS ARTICLE: Sharma S, Singh S, Thomas C. A comparative study of laparotomy wound closed with professor Hughes' far near technique with nylon and interrupted-x technique with vicryl. J. Evolution Med. Dent. Sci. 2019;8(14):1084-1088, DOI: $10.14260 /$ jemds/2019/240

\section{BACKGROUND}

Laparotomy also known as celiotomy is a surgical procedure involving a large incision through abdominal wall to gain access to the peritoneal cavity. Laparotomy may be performed in emergency and elective conditions for diagnosis and treatment of various surgical and gynaecological conditions. Exploratory laparotomy is performed with the intention of obtaining information that is not available via clinical methods. It can be performed in patients with sudden unexplained abdominal pain, in patients with blunt or penetrating abdominal trauma, and occasionally with the intention of staging and biopsy in patients with malignancies.

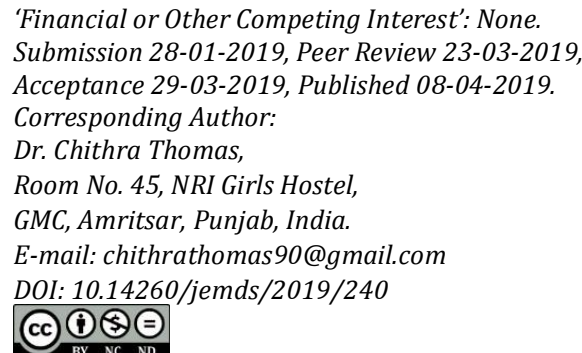

Once the disease condition has been identified, necessary therapeutic procedure is performed; sometimes, it may serve as a means of confirming a diagnosis like malignancy (as in the case of laparotomy and biopsy for intra-abdominal masses that are considered inoperable).

With the increasing availability of contrast enhanced scans and other investigative techniques like diagnostic laparoscopy, the scope of exploratory laparotomy has shrunk over time. As laparoscopy is being used in many centres the need for exploration via laparoscopy has markedly reduced. ${ }^{1}$ Nevertheless, the importance of exploratory laparotomy as a rapid and cost-effective means of managing acute abdominal conditions and trauma especially in developing countries where resources are limited cannot be undermined. In abdominal surgeries wisely chosen incisions and correct techniques of closing such wounds is of great importance. ${ }^{2}$

\section{METHODS}

This Non-randomized controlled trial was conducted with the approval of Institutional Ethics Committee, Government Medical College, Amritsar from July 2016 to August 2018. 40 patients were chosen, irrespective of gender and nature of disease. Sample size was taken for convenience. Out of these 
40 patients, 20 were have the abdominal wall closed by interrupted $\mathrm{X}$ technique and the remaining by Professor Hughes far near technique and they were grouped as group 1 and group 2 respectively.

\section{Inclusion Criteria}

Patients of either sex, aged 15-75 years, who underwent laparotomy elective or emergency with midline incisions.

\section{Exclusion Criteria}

1. Patients who died within 7 days of surgery.

2. Patients who underwent right paramedian, grid iron and transverse incisions.

3. Patients who underwent second laparotomy or relooklaparotomy.

4. Patients with clean wounds.

5. Patients who refused consent.

The required closure was performed accordingly.

\section{Methods of Closure}

Written informed consent was taken from all the patients. Patients were subsequently divided into the following two groups for closure by allotment:

\section{Group 1 (Interrupted- X Closure)}

\section{Techniques of Closure}

The ideal fascial closure should maintain tensile strength throughout the healing process. Here we compare the two methods of compare two methods of closure of aponeurotic sheath.



\section{Group 1-Interrupted-X Technique}

a. A bite is taken at (1) a point $2 \mathrm{~cm}$ from cut edge. The needle emerges at (2) another point $2 \mathrm{~cm}$ from cut edge,
$4 \mathrm{~cm}$ cranial or caudal to (1).

b. The 2 ends of suture strand crossed.

c. The needle enters at (4) and comes out at (3). Point (3) is $4 \mathrm{~cm}$ away from and $2 \mathrm{~cm}$ from cut edge. Point (4) is 4 $\mathrm{cm}$ away from (2) and $2 \mathrm{~cm}$ from cut edge.

d. The two ends of suture being tied in front of linea alba.

e. The small free end of suture pulled inside with an artery forceps or right-angle forceps. The small free end of suture tied with long strand of suture.

f. Not being buried behind linea alba to prevent sinus formation.

g. Two interrupted X-sutures applied $1 \mathrm{~cm}$ apart.

\section{Group 2 (Professor Hughes Far-and-Near Method/Modified Smead-Jones Method)}

This will be performed using no: 1 nylon suture. This comprises a far bite starting $2 \mathrm{~cm}$ on the edge of linea alba from outside-in and then taking a near bite of $0.5 \mathrm{~cm}$ on the other side inside out- a near bite on the same side outside in and a far bite on the other side inside-out using no:1 nylon. Then the suture was converted to horizontal mattress by taking a far bite $1 \mathrm{~cm}$ above or below the previous bite on the other side, then near bite on the same side inside out, near bite on the other side outside in and far bite on the same side inside out. The Smead Jones technique is far simpler. A far stitch is taken outside in a far stitch is taken inside out on the other side then a near stitch is taken outside in on the same side and a near stitch is taken inside out on the other side and a knot is applied.

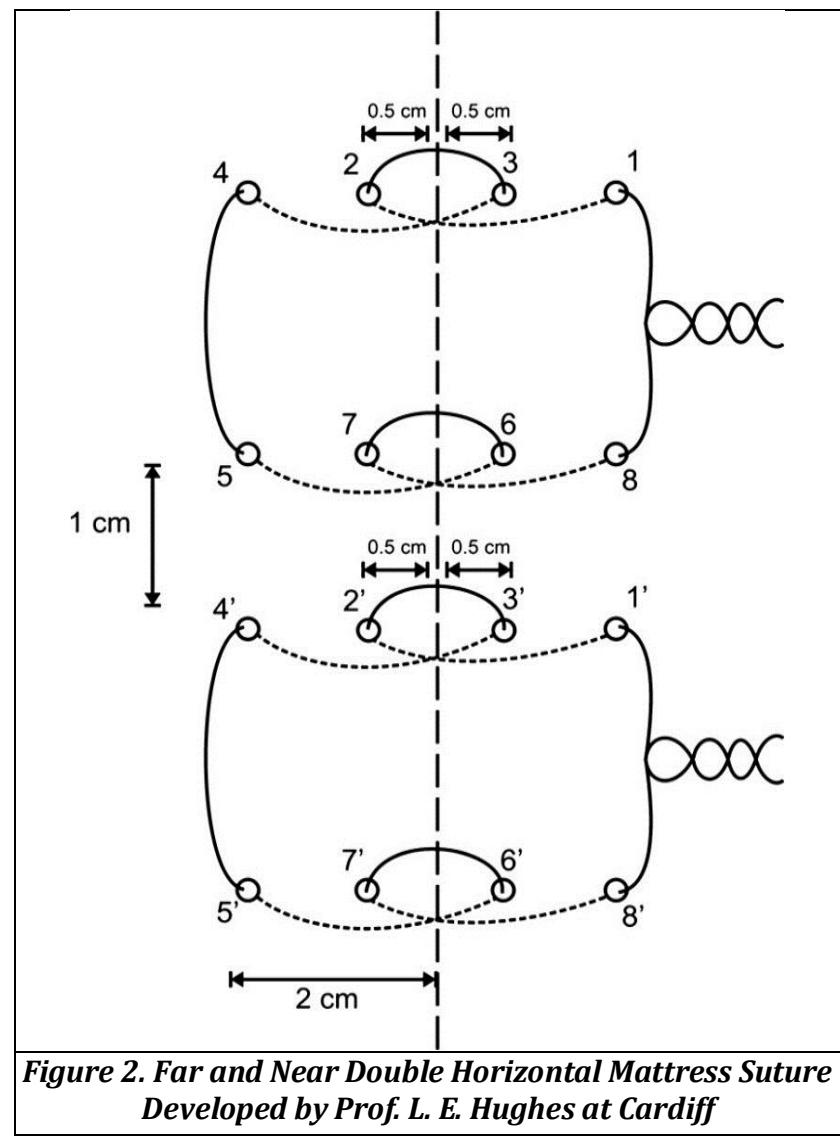

Parameters Evaluated Intra Operatively

Operative time: Time of closure was noted from the starting of the closure of abdominal fascia to the ending of closure. 
Suture length to wound length ratio: The length of the suture material used was divided by the length of the incision and on follow up the patients were examined for following complications: Wound infection, Suture sinus, and Wound dehiscence, Burst abdomen at $3^{\text {rd }}$ post-operative day, at the time of stitch removal and $6^{\text {th }}$ week and later at three months.

\section{Statistical Analysis}

Chi square test $(\chi 2)$ and Fisher exact was used to calculate difference between qualitative variables as indicated. Chi square test was used for comparison of categorical variable data between two groups. Quantitative data were expressed as mean \pm SD (Standard deviation). The significance level for all above mentioned statistical tests was done P-value $\leq 0.05$ indicates significant, $\mathrm{p}<0.001$ indicates highly significant difference while, $\mathrm{P}>0.05$ indicates non-significant difference.

\section{RESULTS}

\section{Group 1}

20 patients who underwent interrupted-X closure of abdominal fascia using no. 1 Vicryl absorbable (polyglactin) suture. The time taken for closure was 31.55 minutes in group 1 with p-value of 0.001 . wound length to suture length ratio was 6.51 . Wound infection rates were $60 \%$ on third post-operative day and $35 \%$ at the time of stitch removal and the relative risk was 3.5 but the results were not statistically significant. Wound dehiscence and burst abdomen rates were $35 \%$ and $20 \%$ at the time of stitch removal respectively.
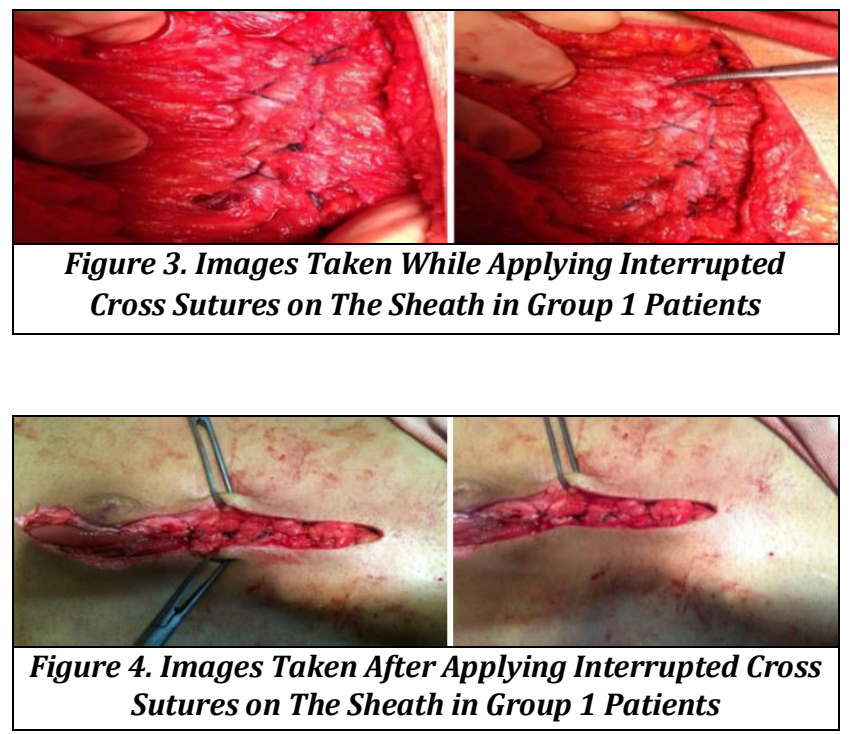

\section{Group 2}

20 patients who underwent Professor Hughes far near closure technique of abdominal fascia using no. 1 nylon sutures. Mean time taken with group 2 patients was 24.50 minutes and wound length to suture length ratio was 5.59. These results were statistically significant. Wound infection rates were $55 \%$ and $10 \%$ on third post-operative day and at the time of stitch removal. Wound dehiscence was $10 \%$ at the time of stitch removal and burst abdomen was absent but these results were not statistically significant.

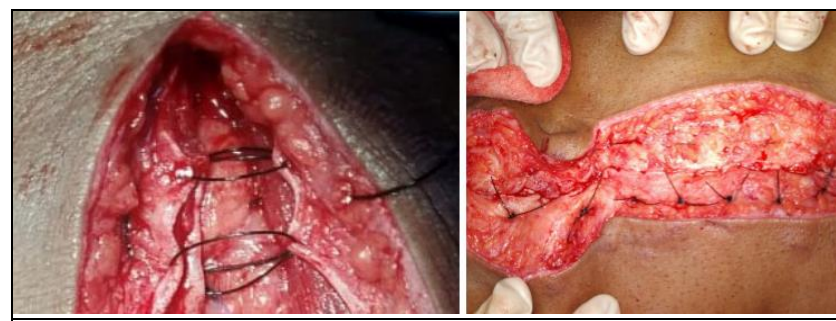

Figure 5. Images Taken While Applying Professor Hughes Far and Near Method on The Sheath in Group 2 Patients
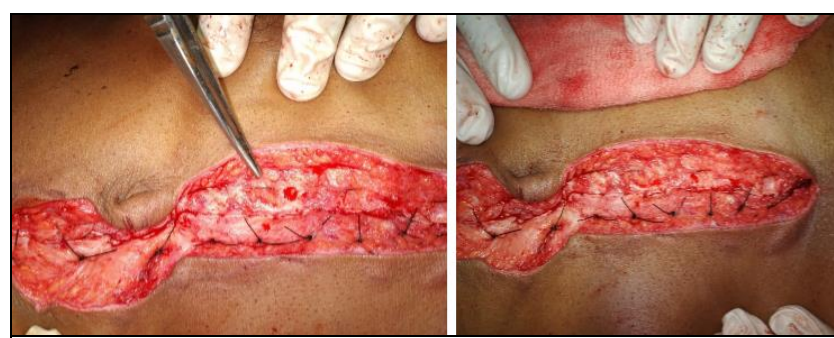

Figure 6. Images Taken After Applying Professor Hughes Far Near Method on The Sheath in Group 2 Patients

\begin{tabular}{|c|c|c|c|c|c|c|}
\hline \multirow{2}{*}{$\begin{array}{l}\text { Time Taken for } \\
\text { Closure }\end{array}$} & \multicolumn{2}{|c|}{ Group 1} & \multicolumn{2}{|c|}{ Group 2} & \multicolumn{2}{|c|}{ Total } \\
\hline & No. & $\%$ & No. & $\%$ & No. & $\%$ \\
\hline$<30$ & 12 & 60.00 & 18 & 90.00 & 30 & 75.00 \\
\hline$>30$ & 8 & 40.00 & 2 & 10.00 & 10 & 25.00 \\
\hline Total & 20 & 100.00 & 20 & 100.00 & 40 & 100.00 \\
\hline Mean \pm SD & \multicolumn{2}{|c|}{$31.55 \pm 0.83$} & \multicolumn{2}{|c|}{$24.50 \pm 3.67$} & \multicolumn{2}{|c|}{$28.02 \pm 7.35$} \\
\hline $\mathrm{p}-\mathrm{va}$ & & & & & & \\
\hline
\end{tabular}

Table I. Comparison of The Time Taken for Closure of Both Groups and Wound Length: Suture Length

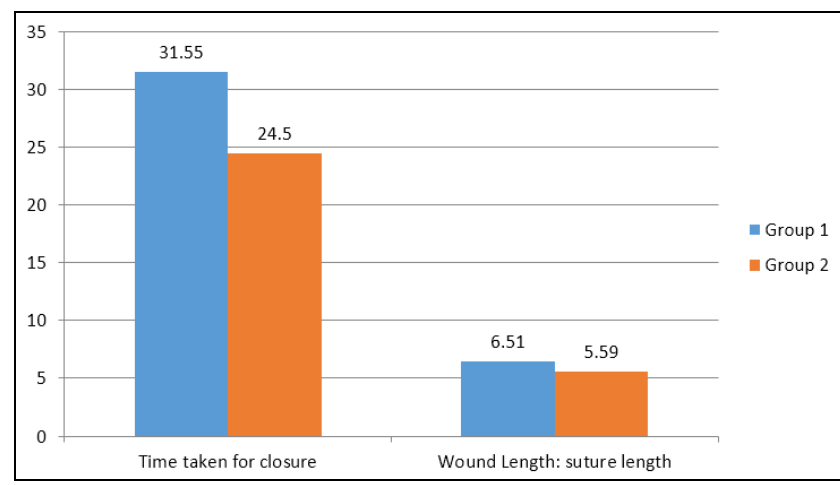

\begin{tabular}{|c|c|c|c|c|c|c|}
\hline \multirow{2}{*}{$\begin{array}{c}\text { Wound } \\
\text { Infection 3rd } \\
\text { Postoperative } \\
\text { Day }\end{array}$} & \multicolumn{2}{|c|}{ Group 1} & \multicolumn{2}{|c|}{ Group 2} & \multicolumn{2}{|c|}{ Total } \\
\hline & No. & $\%$ & No. & $\%$ & No. & $\%$ \\
\hline Absent & 8 & 40.00 & 9 & 45.00 & 17 & 42.50 \\
\hline Present & 12 & 60.00 & 11 & 55.00 & 23 & 57.50 \\
\hline Total & 20 & 100.00 & 20 & 100.00 & 40 & 100.00 \\
\hline p-value & \multicolumn{6}{|c|}{$\mathrm{X} 2: 0.102 ; \mathrm{p}=0.500$} \\
\hline & & & & \multicolumn{3}{|c|}{$95 \% \mathrm{CI}$} \\
\hline Relative Risk & \multicolumn{3}{|c|}{1.091} & \multicolumn{3}{|c|}{$0.640-1.861$} \\
\hline $\begin{array}{r}\text { Table 2. C } \\
P o\end{array}$ & r & of 7 & 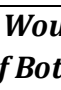 & Groups & tion 3 & \\
\hline
\end{tabular}




\begin{tabular}{|c|c|c|c|c|c|c|}
\hline Wound Infection & \multicolumn{2}{|c|}{ Group 1 } & \multicolumn{2}{c|}{ Group 2 } & \multicolumn{2}{c|}{ Total } \\
\cline { 2 - 7 } 6 Weeks & No. & \% & No. & \% & No. & \% \\
\hline Absent & 19 & 95.00 & 20 & 100.00 & 39 & 97.50 \\
\hline Present & 1 & 5.00 & 0 & 0.00 & 1 & 2.50 \\
\hline Total & 20 & 100.00 & 20 & 100.00 & 40 & 100.00 \\
\hline p-Value & \multicolumn{4}{|c|}{ X2: 1.026; p 0.500} \\
\hline \multicolumn{4}{|c|}{ - } & \multicolumn{3}{c|}{$0.95 \%$ CI } \\
\hline Relative Risk & \multicolumn{4}{|c|}{-} \\
\hline Table 3. Comparison of Wound Infection at 6 Weeks of \\
Both Groups \\
\hline
\end{tabular}

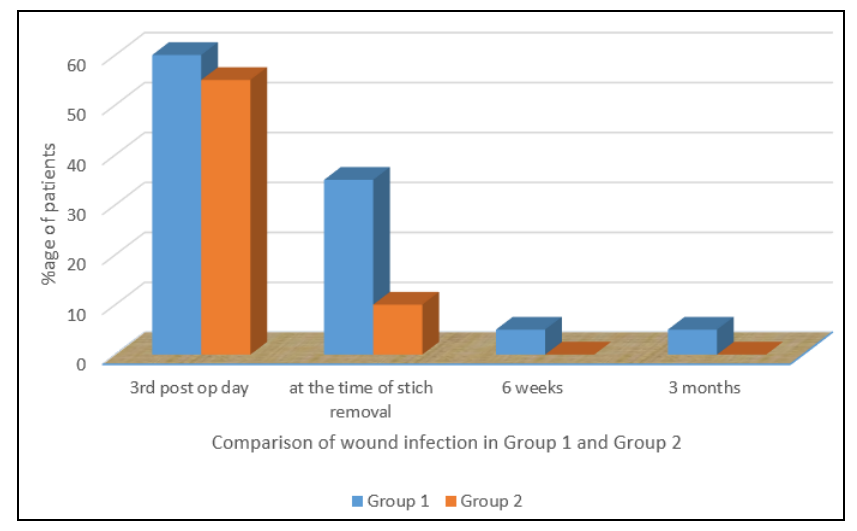

\begin{tabular}{|c|c|c|c|c|c|c|}
\hline \multirow{2}{*}{$\begin{array}{l}\text { Suture Sinus at } \\
\text { the Time of } \\
\text { Stitch Removal }\end{array}$} & \multicolumn{2}{|c|}{ Group 1} & \multicolumn{2}{|c|}{ Group 2} & \multicolumn{2}{|c|}{ Total } \\
\hline & No. & $\%$ & No. & $\%$ & No. & $\%$ \\
\hline Absent & 17 & 85.00 & 15 & 75.00 & 32 & 80.00 \\
\hline Present & 3 & 15.00 & 5 & 25.00 & 8 & 20.00 \\
\hline Total & 20 & 100.00 & 20 & 100.00 & 40 & 100.00 \\
\hline $\mathrm{p}$-Value & \multicolumn{6}{|c|}{$X 2: 0.625 ; p=0.695$} \\
\hline & & & & \multicolumn{3}{|c|}{$0.95 \%$ CI } \\
\hline Relative Risk & \multicolumn{3}{|c|}{0.600} & \multicolumn{3}{|c|}{$0.165-2.180$} \\
\hline \multicolumn{7}{|c|}{$\begin{array}{l}\text { Table 4. Comparison of Suture Sinus Formation at The } \\
\text { Time of Stitch Removal of Both Groups }\end{array}$} \\
\hline
\end{tabular}

\begin{tabular}{|c|c|c|c|c|c|c|}
\hline $\begin{array}{c}\text { Suture Sinus 6 } \\
\text { Weeks }\end{array}$ & \multicolumn{2}{|c|}{ Group 1 } & \multicolumn{2}{c|}{ Group 2 } & \multicolumn{2}{c|}{ Total } \\
\cline { 2 - 7 } & No. & $\mathbf{\%}$ & No. & $\mathbf{\%}$ & No. & \% \\
\hline Absent & 20 & 100.00 & 17 & 85.00 & 37 & 92.50 \\
\hline Present & 0 & 0.00 & 3 & 15.00 & 3 & 7.50 \\
\hline Total & 20 & 100.00 & 20 & 100.00 & 40 & 100.00 \\
\hline p-Value & \multicolumn{6}{|c|}{ X2: 3.240; p=0.231 } \\
\hline \multicolumn{1}{|c|}{-} & \multicolumn{3}{|c|}{$0.95 \%$ CI } \\
\hline Relative Risk & \multicolumn{1}{|c|}{-} \\
\hline Table 5. Comparison of Suture Sinus Formation at 6 Weeks \\
of Both Groups \\
\hline
\end{tabular}



\begin{tabular}{|c|c|c|c|c|c|c|}
\hline \multirow{2}{*}{$\begin{array}{c}\text { Wound } \\
\text { Dehiscence 3rd } \\
\text { Postoperative } \\
\text { Day }\end{array}$} & \multicolumn{2}{|c|}{ Group A } & \multicolumn{2}{|c|}{ Group B } & \multicolumn{2}{|c|}{ Total } \\
\hline & No. & $\%$ & No. & $\%$ & No. & $\%$ \\
\hline Absent & 16 & 80.00 & 18 & 90.00 & 34 & 85.00 \\
\hline Present & 4 & 20.00 & 2 & \begin{tabular}{|l|}
10.00 \\
\end{tabular} & 6 & 15.00 \\
\hline Total & 20 & 100.00 & 20 & 100.00 & 40 & 100.00 \\
\hline p-Value & \multicolumn{6}{|c|}{$\mathrm{X} 2: 0.784 ; \mathrm{p}=0.661$} \\
\hline & & & & \multicolumn{3}{|c|}{$0.95 \% \mathrm{CI}$} \\
\hline Relative Risk & \multicolumn{3}{|c|}{2.000} & \multicolumn{3}{|c|}{$0.412-9.712$} \\
\hline
\end{tabular}

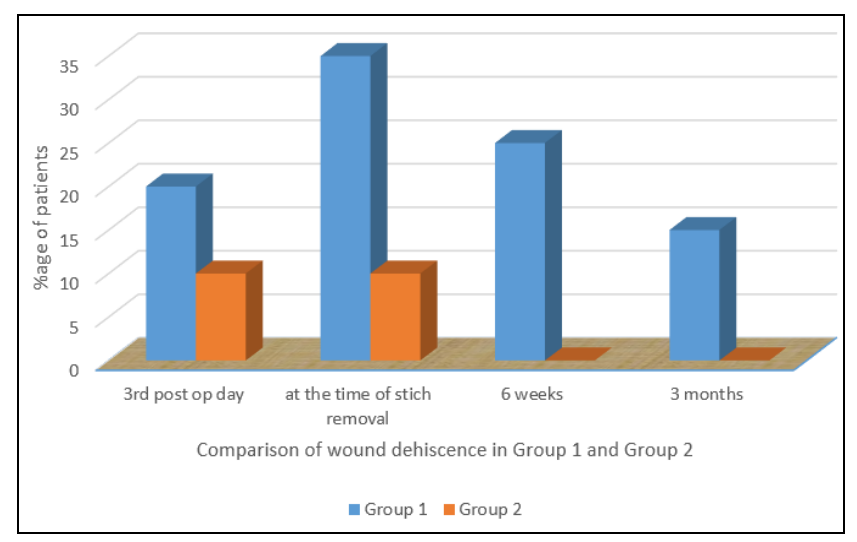

\begin{tabular}{|c|c|c|c|c|c|c|}
\hline \multirow{2}{*}{$\begin{array}{c}\text { Wound } \\
\text { Dehiscence } 6 \\
\text { Weeks }\end{array}$} & \multicolumn{2}{|c|}{ Group 1} & \multicolumn{2}{|c|}{ Group 2} & \multicolumn{2}{|c|}{ Total } \\
\hline & No. & $\%$ & No. & $\%$ & No. & $\%$ \\
\hline Absent & 15 & 75.00 & 20 & 100.00 & 35 & 87.50 \\
\hline Present & 5 & 25.00 & 0 & 0.00 & 5 & 12.50 \\
\hline Total & 20 & 100.00 & 20 & 100.00 & 40 & 100.00 \\
\hline \multirow[t]{2}{*}{ p-Value } & \multicolumn{6}{|c|}{$X^{2}: 5.714 ; p=0.047$} \\
\hline & & & & & \multicolumn{2}{|c|}{$0.95 \% \mathrm{CI}$} \\
\hline Relative Risk & \multicolumn{3}{|c|}{ 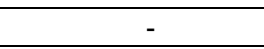 } & \multicolumn{3}{|c|}{-} \\
\hline \multicolumn{7}{|c|}{$\begin{array}{l}\text { Table 7. Comparison of Wound Dehiscence at } 6 \text { Weeks of } \\
\text { Both Groups }\end{array}$} \\
\hline
\end{tabular}

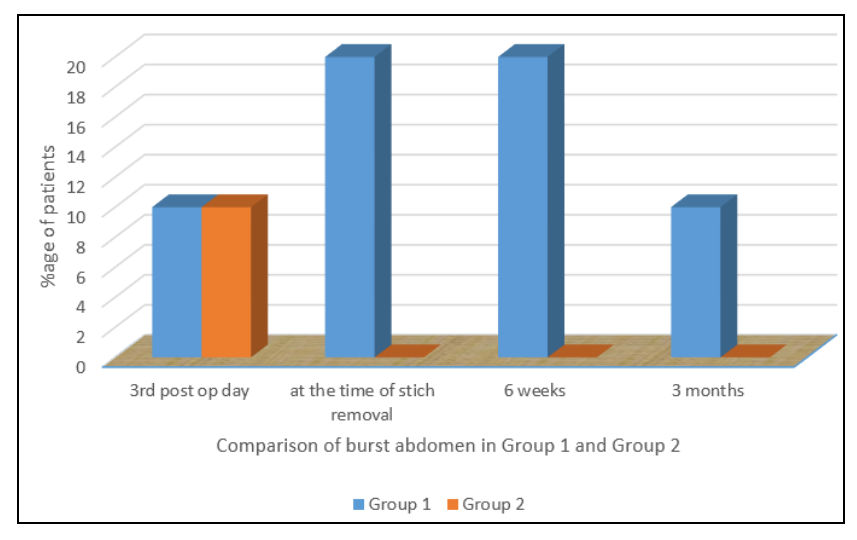

\section{DISCUSSION}

Many methods of abdominal closure have been described but one that maintains tensile strength throughout the healing process with good tissue approximation, does not promote wound infection or inflammation is yet to be definitely 
ascertained. On table many factors can determine the closure of the wound. Because of difficulties arising from differently tailored study designs, the surgical literature has not clearly demonstrated an optimal technique to close abdominal fascia, especially in emergency settings, as patients taken up for elective surgeries are far better prepared to bear the procedure. This Non-randomized controlled trial was undertaken to study and compare the ideal technique and suture for closure of abdominal fascia. The study included 40 patients who underwent exploratory laparotomy in the department of surgery, Guru Nanak Dev Hospital, Amritsar. The patients were further divided equally into two groups namely group 1, interrupted-X and group 2, Professor Hughes far near method of closure of abdominal aponeurotic sheath. The various results and observations have been hereby discussed below.

\section{Time Taken for Closure of Rectus Sheath}

The average time taken for closure in group 1 was $31.55+/-$ 0.83 mins and group 2 was $24.50+/-3.67$ mins. These techniques are time consuming than the continuous method. The $\mathrm{p}$ value was 0.001 hence the difference is highly significant and Professor Hughes suture technique was less time consuming than interrupted- $X$ technique. This is beneficial as patient is kept under anaesthesia for shorter duration. Hence among interrupted sutures Professor Hughes method can be opted as a technique which gives adequate strength and associated with lesser number of complications.

\section{Suture Length and Suture Length to Wound Length Ratio}

Mean length of suture material used in interrupted-X technique was $84.87+/-21.94$ and Professor Hughes technique was $66.81+/-11.98$. The $p$-value was 0.002 hence the difference is statistically significant. Length of suture material is less in Professor Hughes technique compared to interrupted-X. The SL: WL for interrupted-X and Professor Hughes group was $6.51+/-0.51$ and $5.59+/-0.17$ respectively with $\mathrm{p}=0.001$ hence the difference is highly significant. This means Professor Hughes method consumes lesser suture material while maintaining acceptable suture length wound length ratio. ${ }^{3}$ Hence this method is more cost coefficient.

\section{Wound Infection}

Wound infection rate was about $35 \%$ in interrupted-X method at the time of stitch removal and about $10 \%$ in Professor Hughes method. The risk was 3.5 times more with interrupted-X method than Professor Hughes method. ${ }^{4}$

Wound infection for interrupted-X was $5 \%$ at 6 weeks and three months and about $2.5 \%$ for Professor Hughes technique. $\mathrm{P}$ value $=0.5$ hence the difference was not statistically significant. But there was slight decrease in wound infection associated with Professor Hughes method. ${ }^{5}$

\section{Wound Dehiscence}

Wound dehiscence was present in 20\% in group 1 and $10 \%$ in group 2 on the $3^{\text {rd }}$ post-operative day with increased relative risk with interrupted $\mathrm{X}$.

Wound dehiscence was present in 35\% in interrupted-X and $22.5 \%$ in Professor Hughes technique at 6 weeks but the difference was not statistically significant. Wound dehiscence at 3 months was $15 \%$ in interrupted $X$ and none in Professor Hughes technique but the difference was not statistically significant. Studies comparing interrupted $\mathrm{X}$ and professor Hughes technique shows slight decreased in wound dehiscence with Professor Hughes technique.

\section{Suture Sinus}

Suture sinus was present in $15 \%$ and $10 \%$ cases in Professor Hughes technique in 6 weeks and 3 months respectively and none in interrupted-X. But the difference was not found to be statistically significant.

Relative risk was also calculated, and it was found that Professor Hughes method with nylon has more risk for suture sinus formation. Non absorbable sutures have higher chances of suture sinus formations compared to absorbable sutures. ${ }^{6}$

\section{CONCLUSIONS}

1. Wound infection was lower with Professor Hughes' far near technique, but difference was not statistically significant.

2. Wound dehiscence and burst abdomen were low with Professor Hughes' far near technique but difference was not statistically significant

3. Suture sinus was slightly higher in Professor Hughes' technique with nylon than interrupted-X with Vicryl but the difference was not statistically significant.

4. Time consumed was less with Professor Hughes' far near technique and was statistically significant.

5. Length of suture material used was less in Professor Hughes' method while maintaining the SL: WL $>4$ hence cost efficient.

Hence Professor Hughes' far near technique is the preferred method since it causes lesser complications and is time efficient and cost efficient.

\section{ACKNOWLEDGMENTS}

The authors would like to thank all the colleagues in department of general surgery who extended their cooperation, time and cooperation.

\section{REFERENCES}

[1] Mallat AF, Mancini ML, Daley BJ, et al. The role of laparoscopy in trauma: a ten-year review of diagnosis and therapeutics. Am Surg 2008;74(12):1166-70.

[2] Nygaard IE, Squatrito RC. Abdominal incisions from creation to closure. Obstetrical \& Gynecological Survey 1996;51(7):429-36.

[3] Jenkins TPN. The burst abdominal wound: a mechanical approach. Br J Surg 1976;63(11):873-6.

[4] LoCicero J 3rd, Robbins JA, Webb WR. Complications following abdominal fascial closure using various nonabsorbable sutures. Surg Gynecol Obstet 1983;157(1):25-7.

[5] Agrawal CS, Tiwari P, Mishra S, et al. Interrupted abdominal closure prevents burst: randomized controlled trial comparing interrupted-x and conventional continuous closures in surgical and gynecological patients. Indian J Surg 2014;76(4):2706.

[6] Shukla HS, Kumar S, Misra MC, et al. Burst abdomen and suture material: a comparison of abdominal wound closure with monofilament nylon and chromic catgut. Indian J Surg 1981;43:487-91. 